\title{
Neue Elemente des Planeten (470) Kilia.
}

Nachdem eine vorläufige Rechnung die Identität der beiden Planeten (470) Kilia und (489) [1902 JO], vgl. A. N. 3896 , sicher gestellt hatte, habe ich aus beiden Erscheinun. gen unter Berücksichtigung der Jupiterstörungen die folgenden neuen Elemente, die ich für 2 wei verschiedene Oskulations. zeiten anführe, abgeleitet.

$$
\begin{aligned}
& \text { Osk. u. Ep. } 1901 \text { April 9.0 } 1902 \text { Okt. } 2 \text { I.0 Berlin } \\
& M=350^{\circ} 42^{\prime} 5^{\prime \prime !} \\
& \omega=435937.5 \\
& \delta=1731049.4 \\
& i=71321.3 \\
& \varphi=526 \quad 15.2 \\
& \mu=952.3160 \\
& 138^{\circ} 5^{\circ} \quad 9^{\prime \prime} .4 \\
& \begin{array}{llll}
43 & 50 & 52.8
\end{array}
\end{aligned}
$$

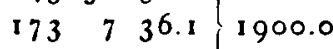

$$
\begin{aligned}
& \begin{array}{lll}
7 & 13 & 40.2
\end{array} \\
& \begin{array}{llll}
5 & 29 & 58.5
\end{array} \\
& 952 \text { 2" } 3542 \\
& 0.380805
\end{aligned}
$$

Die vorhandenen Beobachtungen werden im Sinne $B-R$ wie folgt dargestellt:

$$
\begin{array}{rrrrr} 
& & & & \\
\text { 1901 April 2 I } & \text { Königstuhl } & -3.6 & +0.9 \\
& 23 & : & -11.7 & -2.6 \\
\text { Mai } & 9 & & +2.8 & -3.1
\end{array}
$$

Kiel, Bureau der Astr. Nachr., 1903 Nov. 4.

$$
\begin{aligned}
& \text { ı० I Mai } 14 \text { Königstuhl } \begin{array}{cc}
\Delta \lambda & \Delta \beta \\
+13.6 & +5.0
\end{array} \\
& 1902 \text { Sept. } 3 \text {, } \quad 1.2 \quad-0.7 \\
& \begin{array}{rrrr}
7 & & -15.2 & -0.4 \\
23 & * & +6.4 & +2.6 \\
26 & \text { Wien } & -0.5 & +0.5 \\
\text { Nov. } 3 & * & +12.4 & -2.7
\end{array}
\end{aligned}
$$

Der Planet ist außerdem noch photographisch in König. stuhl 1902 Sept. 8 und Okt. 23 beobachtet worden; die Platten sind aber nicht ausgemessen.

Von den beiden dem Planeten angehörenden Ephemeriden in Veröff. R. I. Nr. 21 ist die erste mit $>(470)$ Kilia bezeichnete wegen der Unsicherheit der zugrunde gelegten Elemente ganz zu streichen; die zweite, unter der Überschrift >(489) [ r 902 JO] s stehende erfordert nach obigen Elementen die Korrektionen:

$\begin{array}{lll}1903 \cdot 04 & \text { in } \alpha & \text { in } 8 \\ \text { Dez. } 23 & -8^{\mathrm{m}} 14^{\mathrm{s}} & +3.2 \\ \text { Jan. } 10 & -824 & +2.0 \\ \text { Febr. } 1 & -74^{6} & -0.4\end{array}$

H. Kreutz.

\section{Vermutete Veränderlicbkeit eines Begleiters von $W$ Andromedae.}

$$
\text { Var. } 62 \text {. } 1903 \text { Andromedae } 2^{h} 8^{\mathrm{m}} 37^{\mathrm{s}}: 2+43^{\circ} 37^{\prime} \cdot 5 \quad 1855 \text { BD. }+43^{\circ} 4^{62} \text {. }
$$

Da der von Anderson im Jahre 1898 entdeckte Ver- I anderer bestätigen zu können, wird es hinreichen, dieselben änderliche W Andromedae (s. A. N. 3539) nach längerer Un- in der folgenden an die Bonner Skala angeschlossenen Form sichtbarkeit eben wieder als Stern I3. bis 14. Größe zum wiederzugeben.

Vorschein kommt, so durfte eine Vorsichtsmaßregel gegenuber dem nächsten aller seiner Vergleichsterne von Nutzen sein. Es ist dieses der Stern BD. $+43^{\circ} \cdot 462$, welcher dem Veränderlichen auf demselben Parallel um $11^{\text {s.6 }}$ nachfolgt. Derselbe scheint seit drei Jahren einer stetigen und lang. samen Helligkeitsänderung von einer Größenklasse unterworfen gewesen zu sein. Will man ihn trotzdem seiner bequemen Lage halber als Vergleichstern benutzen, so hat man nur die von allen Algol-Beobachtern in bezug auf $\rho$ Persei befolgte Vorsicht anzuwenden, den Stern an jedem Beobachtungstage an andere unveränderliche Vergleichsterne anzuschließen.

Um die wenigen bei Herstellung der Karte gemachten Beobachtungen durch den Vergleich mit den Beobachtungen

Georgetown College Observatory, 1903 Nov. 20.

$\begin{array}{lrccc}\text { Datum } & \text { Luft } & \text { Stufen } & \text { Größe } \\ 1900 \text { Nov. } 12 & \text { II } & 34.2 & 9.9 \\ 1901 \text { Febr. } 6 & \text { III } & 13.8 & 9.2 \\ & 10 & - & 13.8 & 9.2 \\ \text { Okt. } 15 & \text { I } & 13.8 & 9.2 \\ \text { Nov. 2 } 1 & \text { CI } & 13.2 & 9.2 \\ 1902 \text { Okt. } 8 & \text { I } & 4.0 & 8.9 \\ 1903 \text { Sept. 22 } & \text { - } & 1.0 & 8.8 \\ & 24 & \text { II } & 0.0 & 8.8 \\ \text { Okt. 20 } & \text { II } & 1.0 & 8.8 \\ \text { Nov. 18 } & \text { II } & 4.0 & 8.9\end{array}$

Die BD. gibt dem Stern die Größe 9.5, Anderson 9.7 (Dez. 1898 ). Die Farbe des Sternes ist vier nach Chandlers Skala, oder RG nach der Potsdamer Bezeichnung.

$$
\text { F. G. Hagen, S. J. }
$$

\section{Literarische Anzeige.}

G. Schiaparelli. L' astronomia nell' antico testamento. Milano, Hoepli 1903.

Der Verfasser der Vorlăufer des Kopernikus im Altertum und der shomozentrischen Sphären des Eudoxus \& hat uns hier mit einer neuen historischen Abhandlung beschenkt, die sicher dieselbe Beachtung wie die früheren finden wird. 